\title{
Social Exchange in Organizations: Perceived Organizational Support, Leader-Member Exchange, and Employee Reciprocity
}

\author{
Randall P. Settoon and Nathan Bennett \\ Louisiana State University
}

\author{
Robert C. Liden \\ University of Illinois at Chicago
}

\begin{abstract}
Social exchange (P. Blau, 1964) and the norm of reciprocity (A. W. Gouldner, 1960) have been used to explain the relationship of perceived organizational support and leader-member exchange with employee attitudes and behavior. Recent empirical research suggests that individuals engage in different reciprocation efforts depending on the exchange partner (e.g., B. L. McNeely \& B. M. Meglino, 1994). The purpose of the present study was to further investigate these relationships by examining the relative contribution of indicators of employee-organization exchange and subordinate-supervisor exchange. Structural equation modeling was used to compare nested models. Results indicate that perceived organizational support is associated with organizational commitment, whereas leader-member exchange is associated with citizenship and in-role behavior.
\end{abstract}

The concepts of social exchange (Blau, 1964) and the norm of reciprocity (Gouldner, 1960) have long been used by organizational researchers to describe the motivational basis behind employee behaviors and the formation of positive employee attitudes (e.g., Etzioni, 1961; Levinson, 1965; March \& Simon, 1958). More recently, these concepts have been used to explain why individuals express loyalty to the organization (e.g., Scholl, 1981; Eisenberger, Huntington, Hutchison, \& Sowa, 1986) and engage in behaviors that typically are neither formally rewarded nor contractually enforceable (e.g., Organ, 1988; Rousseau, 1989). In general, research findings suggest that positive, beneficial actions directed at employees by the organization and/or its representatives contribute to the establishment of high-quality exchange relationships (e.g., Dansereau, Graen, \& Haga, 1975; Konovsky \& Pugh, 1994) that create obligations for employees to reciprocate in positive, beneficial ways (e.g., Eisenberger et al., 1986; Shore \& Wayne, 1993).

The present study was designed to more closely exam-

Randall P. Settoon and Nathan Bennett, Department of Management, Louisiana State University; Robert C. Liden, Department of Management, University of Illinois at Chicago.

We thank Kevin Mossholder and Bruce Meglino for their helpful comments on drafts of this article. An earlier version of this article was presented at the 1995 Southern Management Association Annual Meeting, Orlando, Florida.

Correspondence concerning this article should be addressed to Randall P. Settoon, Department of Management, Louisiana State University, Baton Rouge, Louisiana 70803-6312. Electronic mail may be sent via Internet to fmgt2646@selu.edu. ine social exchange and reciprocity as they relate to worker behavior and attitudes. We examined two levels of social exchange that to this point have been investigated separately: exchange among employees and (a) the organization and (b) their immediate supervisor. Actions indicating positive regard for employees attributable to the organization and/or the supervisor purportedly create feelings of obligation that serve to increase functional behavior (Shore \& Wayne, 1993; Wayne \& Green, 1993). More specifically, recipients of positive actions experience a sense of indebtedness that is highly aversive and can be reduced through reciprocation (Greenberg, 1980). Furthermore, individuals seek to reciprocate in ways that maximize the likelihood that the partner to the exchange will notice this effort (Blau, 1964; Gouldner, 1960 ). Only when the donor is benefited through the effort of the recipient is that sense of indebtedness reduced (Greenberg \& Westcott, 1983). In support of this, recent empirical work has found employees to direct reciprocation efforts toward the source of benefits received (McNeely \& Meglino, 1994).

In the present study, the relative contribution of different exchange relationships to important employee outcome variables was examined. In-role behavior, citizenship behavior, and organizational commitment were selected as focal dependent variables for several reasons. First, these variables have been shown to be salient with respect to a variety of exchange relationships. For example, empirical research has found in-role behaviors, such as attendance (Eisenberger et al., 1986) and performance (Graen, Novak, \& Sommerkamp, 1982; Wayne \& Ferris, 1990 ), citizenship (Konovsky \& Pugh, 1994; Moorman, 
1991; Organ \& Konovsky, 1989; Shore \& Wayne, 1993; Wayne \& Green, 1993), and organizational commitment (Robinson, Kraatz, \& Rousseau, 1994; Shore \& Wayne, 1993) to be associated with actions on the part of the organization and its representatives that seemingly demand reciprocity (e.g., support for employees or fair decision-making).

Second, employees purportedly view in-role behavior, citizenship, and organizational commitment as acceptable commodities for exchange. For example, extra effort in performing required duties (i.e., in-role behaviors) is one way employees can fulfill obligations to employers (cf. Etzioni, 1961; Katz \& Kahn, 1966; Levinson, 1965; March \& Simon, 1958). Likewise, citizenship behavior has been viewed as a social resource that may be exchanged by individuals who have been the recipient of social rewards (Foa \& Foa, 1980; Moorman, 1991). The discretionary nature of extra-role behavior such as citizenship means they may easily be given or withheld (Katz \& Kahn, 1966; Organ, 1988); this makes them ideal wares for reciprocation. In addition, Scholl (1981) suggested that reciprocity is a mechanism underlying commitment. Debt incurred through rewards given by the organization acts to hold an individual into a particular system until the debt is repaid. Others have suggested that organizational commitment may be construed as an "array of obligations" (Robinson et al., 1994, p. 149) incurred as a result of inducements accepted from the organization.

\section{Theoretical Background}

Blau (1964) suggested that the basis of any exchange relationship can be described in terms of either social or economic principles. Exchanges that are social in nature are based on a trust that gestures of goodwill will be reciprocated at some point in the future. The specific benefits exchanged may be valued primarily because they are symbols of a high-quality relationship; it is the exchange of mutual support that is of concern to the parties involved in the exchange (Blau, 1964).

The two main ways social exchange has been conceptualized in the management literature are a global exchange relationship between employees and the organization and a more focused, dyadic relationship between subordinates and their superiors. At the global level, Eisenberger et al. (1986) suggested that employees form a global belief concerning the extent to which the organization values their contributions and cares about their well-being. They labeled this belief perceived organizational support. High levels of perceived organizational support are thought to create obligations within individuals to repay the organization. Furthermore, perceived organizational support is associated with a trust that the organization will fulfill its exchange obligations (e.g., rewarding employees). Empirical research has found perceived organizational support to be positively related to performance of conventional job responsibilities, citizenship behavior, and commitment (Eisenberger et al., 1986; Eisenberger, Fasolo, \& Davis-LaMastro, 1990; Shore \& Wayne, 1993).

Social exchange has also been used to explain why subordinates become obligated to their supervisors to perform in ways beyond what is required of them in the formal employment contract. Research on leader-member exchange has shown that there is variance among subordinates in the frequency with which they engage in activities that extend beyond the employment contract (Liden \& Graen, 1980; Wayne \& Green, 1993). However, employment contracts vary in terms of the nature and amount to be exchanged. Members who benefit greatly from their formal contracts, even those with low leadermember exchange relationships, may feel obligated and willing to contribute to the organization.

\section{Hypotheses and Proposed Model}

The model appearing in Figure 1 depicts (with solid lines) the differences in relations between the type of social exchange and employee attitudes and behaviors. Exchange with the organization, reflected in perceived organizational support, is expected to be associated with organizational commitment. Research has demonstrated that employees are differentially committed to multiple foci such as top management, supervisors, and coworkers (Becker, 1992; Mathieu \& Zajac, 1990; Reichers, 1986). This multidimensional approach to organizational commitment suggests that commitment with the organization as a focus should be more highly related to positive discretionary actions on the part of the organization than positive discretionary acts attributable to other foci such as the supervisor (Reichers, 1985). In this respect, perceived organizational support has been described as an individual's perception of the organization's "commitment" to its employees. As such, an individual's expressed dedication and loyalty to the organization would appear to be a reasonable and comparable return (Eisenberger et al., 1990; Robinson et al., 1994). Thus, we predict a positive relationship between perceived organizational support and organizational commitment.

As leader-member exchanges increase in quality, supervisors enlist the help of subordinates on various tasks by offering valued inducements such as influence and support (Graen \& Scandura, 1987). Such supervisor contributions create obligations to reciprocate. By expending time and effort fulfilling supervisor requests or engaging in extra-role behaviors that benefit the supervisor, such as working overtime with the supervisor on a 


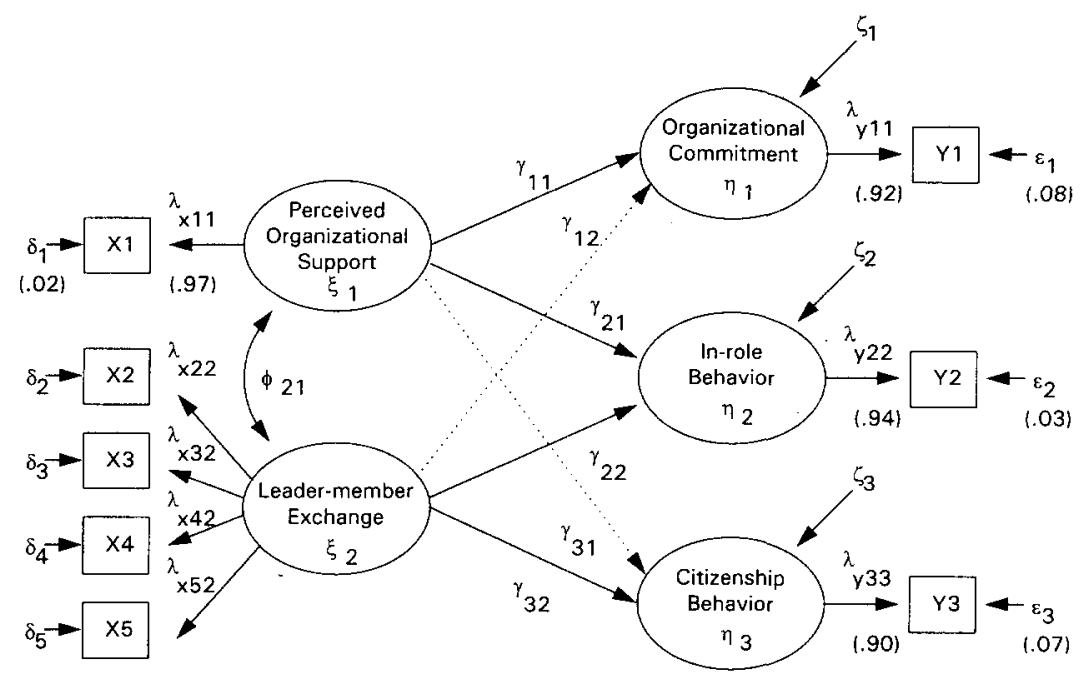

Figure 1. Model of social exchange. Numbers in parentheses are values for constrained paths.

task or helping a coworker with a task on which the supervisor is dependent, subordinates directly reciprocate benefits received and maintain a high-quality leadermember exchange (Wayne \& Green, 1993).

The citizenship behavior examined in the current study is help-oriented behavior directed toward others. This type of citizenship has been characterized as "interpersonal behavior" having "consequences for interpersonal relationships" (Van Dyne, Graham, \& Dienesch, 1994 , p. 794), as opposed to behavior having ramifications for organizations. Because help-oriented citizenship has immediate consequences for others, we hypothesized a positive relationship between leader-member exchange and citizenship behavior.

Finally, we hypothesized positive relationships between perceived organizational support and in-role behaviors and between leader-member exchange and inrole behaviors (e.g., proper discharge of work responsibilities as specified in the job description, etc.), which have obvious benefits for both the supervisor and the organization. We compared our model to plausible alternative models (indicated by dashed lines in Figure 1), thus providing a rigorous test of the hypotheses (Platt, 1964).

\section{Method}

\section{Sample and Procedure}

Respondents were employed by a regional hospital located in a major metropolitan area in the southern United States. There were 254 nonsupervisory employees from 28 work groups randomly selected for participation in the study. Surveys were distributed to these employees through the hospital's interdepartmental mail. Respondents returned completed surveys to the researchers through the U.S. mail with addressed, postage-paid envelopes. Participants provided the last four digits of their Social Security numbers so that their responses could be categorized by work group and assigned to the appropriate supervisor. In all, 124 surveys were returned for an overall response rate of $49 \%$ and an average group response rate of $42 \%$. Because of missing data, 22 of the surveys returned were unusable. As a result, 102 employees comprised the final subordinate sample. Of these, $85 \%$ were women and $86 \%$ were White. The average age was 34.7 years $(S D=12.7)$, and the average tenure with the company was 5.7 years $(S D=4.9)$.

There were 26 supervisors (a response rate of $93 \%$ ) who completed separate questionnaires, one for each of their subordinates chosen for the study. Of the supervisors, $81 \%$ were women and $92 \%$ were White. The mean age of the supervisors was 39 years $(S D=7.2)$, and the mean number of years as a supervisor was $4.6(S D=4.3)$.

\section{Measures}

Subordinates completed perceived organizational support, leader - member exchange, and organizational commitment scales. Supervisors responded to citizenship and in-role behavior scales. Respondents used 5-point Likert scales ranging from strongly disagree to strongly agree to respond to all items. We coded items such that a high score reflects a high level of the focal construct.

Perceived organizational support. Perceived organizational support ( $\alpha=.94$ ) was measured with eight items from the short version of the Survey of Perceived Organizational Support (Eisenberger et al., 1986). The survey assesses employee valuations of the organization and actions it might take in situations that affect employee well-being.

Leader-member exchange. The quality of the exchange between supervisor and subordinate was assessed with the Multidimensional Measure of Leader-Member Exchange developed by Liden and Maslyn (1993). The measure includes four sub- 
scales: loyalty $(\alpha=.92)$, respect $(\alpha=.78)$, contribution ( $\alpha=$ $.70)$, and affect $(\alpha=.96)$.

Organizational commitment. Organizational commitment was measured with nine positively worded items from the Organizational Commitment Questionnaire ( $\alpha=.84$; Mowday, Steers, \& Porter, 1979). We used these items rather than the full 15 -item scale because several researchers have suggested that the six negatively keyed items measure an intent-to-quit factor (e.g., Carsten \& Spector, 1987; Farkas \& Tetrick, 1989; Michaels \& Spector, 1982; Williams \& Hazer, 1986). We conducted a confirmatory factor analysis of the 15 -item Organizational Commitment Questionnaire and found that a two-factor model with the negatively keyed items loading on one factor and the positively worded items loading on the other, was superior to a one-factor solution.

Citizenship and in-role behaviors. Citizenship behavior directed at individuals and in-role behavior were measured with two scales developed by Williams and Anderson (1991). Supervisors evaluated the degree to which subordinates engaged in behaviors that aided them and other coworkers but were not part of the subordinate's required duties. Seven items measured citizenship behaviors directed at the supervisor and coworkers $(\alpha=.81$; "The employee helps others who have heavy workloads"). Also, supervisors were asked to evaluate the extent to which subordinates fulfilled those job responsibilities that are formal and required. Seven items measured in-role behaviors ( $\alpha=.89$; "The employee fulfills responsibilities specified in the job description").

\section{Analyses}

Structural equation modeling (LISREL VIII) was used to test the model presented in Figure 1. A covariance matrix was used as input for estimation of the measurement and structural models. In order to provide strong support for our theoretical model, we used a nested-models comparison procedure (Bentler \& Bonett, 1980). This procedure addresses the prediction that the constrained or restricted paths in the nested models hypothesized to be zero are indeed zero (James, Mulaik, \& Brett, 1982). In the comparison procedure, a nonsignificant chi-square difference between two models suggested that the more restricted model is a better model because greater parsimony is achieved without a significant decrease in the overall fit of the model.

The model in Figure 1, which includes all paths (both solid and dashed), was used as the basis for the nested-models comparison procedure and is referred to as Model 1. From this model, we proceeded by constraining successive paths to zero and examining the change in the fit indices. After identification of the best-fitting model, the significance of the individual paths between the constructs was assessed to provide more of a detailed analysis of the relationships among the constructs.

There are two reasons we chose to use scale scores as indicators rather than individual items as indicators of our latent variables. First, there are LISREL computing limitations and difficulties fitting models with more than $\mathbf{3 0}$ manifest indicators (Bentler \& Chou, 1987; Moorman, 1991; Williams \& Hazer, 1986). In our study, we had 44 manifest indicators ( or items).

Second, the number of parameters estimated relative to sam- ple size is an important determinant of convergence, standard errors, and model fit in covariance structure models (Hayduk, 1987). A sample-size-to-parameter ratio of 5 or more is sufficient to achieve reliable estimates in maximum likelihood estimation (Bentler, 1985). Hence, when dealing with moderate sample sizes, as is the case with this study, a parsimonious estimation strategy is necessary.

Following the procedures outlined by Kenny (1979) and Williams and Hazer (1986), we created manifest indicators for each latent variable by averaging the items for each scale (in the case of unidimensional scales) or each subscale (in the case of the leader-member exchange scale). For the unidimensional scales, we used the reliability $(\alpha)$ to calculate the factor loading and measurement error for each manifest variable. The path from the latent variable to its manifest indicator (i.e., $\lambda$ ) was set to the square root of the reliability of the measured variable. As a covariance matrix was used as input, we set the error variance for each manifest indicator to the product of the variance of the average of the items by scale and the quantity one minus the reliability of the scale. The values at which the factor loadings and error variances were set appear in parentheses in Figure 1.

Unlike the other measures used in this study, the Liden and Maslyn (1993) scale gauges multiple dimensions of leadermember exchange. Because we wanted to preserve the integrity of the constructs we were measuring, we decided to use the four subscales as manifest indicators of the leader-member exchange latent variable. This decision was supported by preliminary analyses comparing the results of first- and second-order confirmatory factor analyses. Specifically, we conducted a confirmatory factor analysis on the leader-member exchange items and found a four-factor solution was consistent with the data; $\chi^{2}(59, N=95)=165.82$; normed fit index $(\mathrm{NFI})=.91$; comparative fit index $(\mathrm{CFI})=.94$; goodness of fit $(\mathrm{GFI})=.79$. All items loaded significantly on designated factors (i.e., loyalty, respect, contribution, and affect) and the modification indices did not indicate any cross-loadings. Liden and Maslyn (1993) found that the four factors loaded on a single second-order factor they proposed to be a general leader-member exchange dimension. We replicated the second-order factor analysis and found that a model with the four first-order factors loading on one general second-order factor fit equally well; $\chi^{2}(61, N=95)$ $=172.0 ; \mathrm{NFI}=.90 ; \mathrm{CFI}=.94 ; \mathrm{GFI}=.80$. Thus, for the leadermember exchange latent variable, we used the four subscales of the Liden and Maslyn (1993) leader-member exchange scale as multiple manifest indicators of a general leader-member exchange factor rather than creating a single indicator from all of the items and fixing the factor loading and measurement error.

\section{Results}

Descriptive statistics for all of the variables used in the study are reported in Table 1. Following the procedure outlined by Anderson and Gerbing (1988), confirmatory factor analyses were conducted to determine that the data conform with the supposition that each of the proposed latent variables represents separate constructs. Results revealed a nonsignificant chi-square; $\chi^{2}(14, N=95)=$ $24.34, p>.01$. Additionally, the GFI $=.94$, the NFI $=$ 
Table 1

Means, Standard Deviations, Intercorrelations, and Covariances of Measures

\begin{tabular}{|c|c|c|c|c|c|c|c|c|c|c|}
\hline Measure & $M$ & $S D$ & 1 & 2 & 3 & 4 & 5 & 6 & 7 & 8 \\
\hline $\begin{array}{l}\text { 1. Perceived organizational } \\
\text { support }\end{array}$ & 258 & 0.4 & 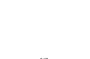 & 058 & & & & & & \\
\hline 2. Loyalty & $\begin{array}{l}3.50 \\
3.59\end{array}$ & $\begin{array}{l}0.04 \\
1.07\end{array}$ &.$\overline{60 * *}$ & 0.38 & $\begin{array}{l}0.38 \\
1.07\end{array}$ & $\begin{array}{l}0.00 \\
1.00\end{array}$ & $\begin{array}{l}0.00 \\
1.04\end{array}$ & $\begin{array}{l}0.09 \\
0.27\end{array}$ & $\begin{array}{l}0.28 \\
0.25\end{array}$ & $\begin{array}{l}0.08 \\
0.17\end{array}$ \\
\hline 3. Respect & 3.79 & 1.12 & $.58^{* *}$ & $.90^{* *}$ & - & 1.02 & 1.01 & 0.23 & 0.21 & 0.15 \\
\hline 4. Contribution & 3.60 & 1.07 & $.63^{* *}$ & $.87^{* *}$ & $.85^{* *}$ & - & 0.91 & 0.26 & 0.26 & 0.13 \\
\hline 5. Affect & 3.63 & 1.07 & $.53^{* *}$ & $.91^{* *}$ & $.87^{* *}$ & $.81^{* *}$ & - & 0.24 & 0.19 & 0.18 \\
\hline $\begin{array}{l}\text { 6. Organizational } \\
\text { citizenship behavior } \\
\text { 7. Organizational }\end{array}$ & 3.66 & 0.60 & .18 & $.42^{* *}$ & $.36^{* *}$ & $.41^{* *}$ & $.40^{* *}$ & - & 0.04 & 0.17 \\
\hline commitment & 4.09 & 0.55 & $.58^{* *}$ & $.37^{* *}$ & $.29^{* *}$ & $.41^{* *}$ & $.28^{* *}$ & .13 & - & 0.00 \\
\hline 8. In-role behavior & 4.20 & 0.56 & .18 & $.32^{* *}$ & $.28^{* *}$ & $.24^{*}$ & $.34^{* *}$ & $.57^{* *}$ & .01 & - \\
\hline
\end{tabular}

Note. Covariances appear above the diagonal.

${ }^{*} p<.05 .{ }^{* *} p<.01$.

.96 , and the CFI $=.98$, all exceeding the recommended level of .90 . These indices measure the difference between the covariance matrix predicted by the model and the one resulting from the sample data. In summary, the measurement relationships proposed were consistent with the data.

In order to provide additional support for our measurement model, we created multiple indicators for each latent variable and repeated the confirmatory factor analysis. Multiple indicators were created through exploratory factor analyses conducted on each unidimensional variable (that is, all variables except leader-member exchange). We forced a one-factor solution in each instance and proceeded to combine (average) the highest loading item and the lowest loading item to form the first indicator, the next highest loading item and the next lowest loading item to form the second indicator, and so forth. In situations where there were an odd number of items comprising a scale, the last indicator included two items plus the median item. This procedure resulted in a measurement model that included four indicators of perceived organizational support, four indicators of organizational commitment, three indicators of in-role behavior, and three indicators of citizenship behavior. Consistent with the manifest indicators approach, we used the four dimensions of the leader-member exchange scale as indicators of the leader-member exchange latent variable. A confirmatory factor analysis revealed that this model had adequate fit; $\chi^{2}(125, N=95)=207.57$; NFI $=.87$; CFI $=.94$; GFI $=.83$; and that all indicators loaded significantly on their hypothesized factors. Although each of these analytic approaches (i.e., manifest indicator approach and multiple indicator approach) resulted in a measurement model with adequate fit, it should be noted that the sample-size-to-parameter ratio in the latter approach was near 2 to 1 , which is well below the generally accepted ratio of 5 to 1 .
The chi-square values, associated degrees of freedom, and probability levels for the evaluated structural models are presented in Table 2. Also reported in Table 2 are the GFI, the NFI, and the CFI. As shown, Model 1 had an adequate fit; $\chi^{2}(17, N=95)=56.19$; with the fit indices either exceeding or approaching the commonly accepted threshold value of $.90(\mathrm{NFI}=.91, \mathrm{CFI}=.94$, and $\mathrm{GFI}$ $=.88$ ).

The results of the first nested-models comparison test indicated that Model 2, which restricted to zero the path between perceived organizational support and citizenship, resulted in a nonsignificant change in the fit of the model to the data; $\Delta \chi^{2}(1, N=95)=1.70$. Therefore, Model 1 was rejected. The results of the second nestedmodels comparison test (i.e., Model 3 compared with Model 2) also yielded a nonsignificant decrease in fit; $\Delta \chi^{2}(1, N=95)=.12$. In other words, restricting the path between leader-member exchange and organizational commitment to zero resulted in a model that fit the data equally well, but had the advantage of greater parsimony. In summary, the results of the nested-models comparison procedure offer support for our proposed model.

Figure 2 presents the maximum likelihood parameter estimates from a standardized solution. As hypothesized, leader-member exchange was related to citizenship and in-role behavior. Additionally, perceived organizational support was related to organizational commitment. However, perceived organizational support was not related to in-role behaviors as hypothesized.

We also evaluated the proposed structural model with the multiple indicator approach described above in order to determine if the results would differ from the results of the manifest indicator approach. The results of the nested-models analysis showed that the fit indices were weaker than those calculated with the manifest indicators approach and the structural parameter estimates were 
Table 2

Results of Nested-Models Comparison Procedure

\begin{tabular}{lcccccc}
\hline \multicolumn{1}{c}{ Model } & $d f$ & $\chi^{2}(N=95)$ & $\Delta \chi^{2}(N=95)^{\mathrm{a}}$ & NFI & CFI & GFI \\
\hline $\begin{array}{l}\text { Model 1 } \\
\begin{array}{l}\text { Model 2 } \\
\quad \text { Perceived organizational support } \\
\quad \text { organizational citizenship } \\
\quad \text { behavior }\end{array}\end{array}$ & 17 & 56.19 & & .91 & .94 & .88 \\
$\begin{array}{l}\text { Model 3 } \\
\quad \text { Leader-member exchange } \rightarrow \\
\quad \text { organizational commitment }\end{array}$ & 18 & 57.89 & 1.70 & .91 & .93 & .88 \\
\begin{tabular}{l} 
Structural null \\
\hline
\end{tabular} & 19 & 58.01 & 0.12 & .91 & .94 & .88 \\
\hline
\end{tabular}

Note. $\quad \mathrm{NFI}=$ normed fit index $; \mathrm{CFI}=$ comparative fit index $; \mathrm{GFI}=$ goodness-of-fit index.

${ }^{a}$ Calculated from adjacent models. ${ }^{b}$ Path constrained to zero.

$* p<.05$.

somewhat attenuated. However, the parameter estimates remained significant, and the results of the nested models comparison tests were the same as those with the manifest indicators approach. The proposed theoretical model was still the superior model. Again, it should be noted that the sample-size-to-parameter estimate was well below the standard suggested by Bentler (1985) and was achieved with the manifest indicator approach.

\section{Discussion}

The purpose of the current study was to determine whether exchange relationships among employees, the organization, and their immediate supervisors explain different employee behaviors. Structural equation modeling results considered on the combined criteria of fit and parsimony showed that these two exchange relationships were differentially related to employee behaviors.

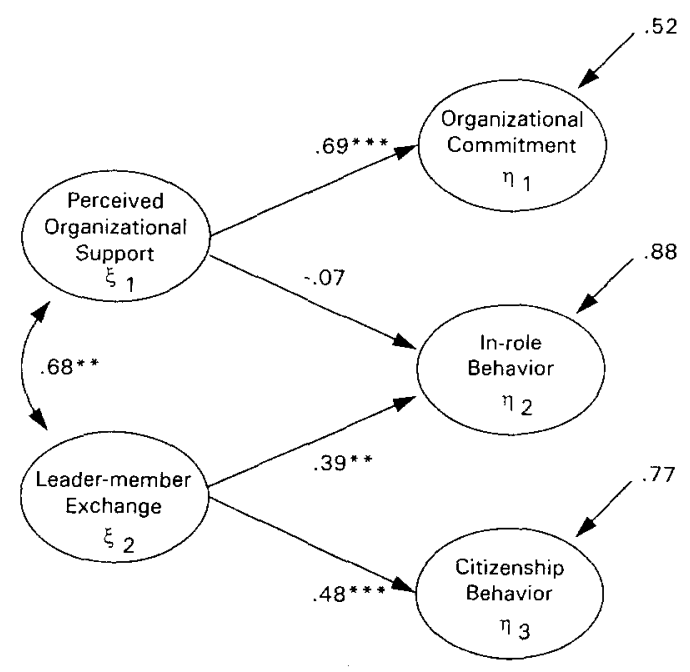

Figure 2. Structural parameter estimates. ${ }^{* *} p<.01 . \quad{ }^{* * *} p$ $<.001$.
Specifically, perceived organizational support was a stronger correlate of organizational commitment than leader-member exchange. Conversely, leader-member exchange was more highly related to citizenship than perceived organizational support.

The results suggest that desired work behaviors, both those that conform with and those that extend beyond what is specified in the employment contract, are associated with the nature of the relationship with the supervisor. The more that relationships or exchanges between supervisors and subordinates are based on mutual trust and loyalty, interpersonal affect, and respect for each other, the better the subordinate's performance in terms of expected and "extra" or citizenship behaviors. Although studies have found positive correlations between perceived organizational support and citizenship behaviors (Shore \& Wayne, 1993) and between leader-member exchange and citizenship behaviors (Wayne \& Green, 1993), the current study shows that when both leadermember exchange and perceived organizational support are examined within the same study, leader-member exchange has a stronger association with citizenship behavior than does perceived organizational support. Similarly, studies have shown that organizational commitment is related to perceived organizational support (Shore \& Wayne, 1993) and leader-member exchange (Manogran \& Conlon, 1993). However, results of the current study suggest that when leader-member exchange and perceived organizational support are examined within the same study, perceived organizational support dominates leader-member exchange in explaining variance in organizational commitment.

Although we hypothesized in the proposed model that both perceived organizational support and leader-member exchange would be related to in-role behaviors, results showed that the path from leader-member exchange to in-role behaviors, but not from perceived organizational support to in-role behaviors, was statistically sig- 
nificant. It may be that because the organization under study was hierarchically structured, in-role behaviors were under the direct control of immediate supervisors. Thus, leader-member exchange dominated perceived organizational support in explaining in-role behaviors. In flatter, more organically structured organizations in which supervisors have less well-structured control over the behavior of employees perceived organizational support might have a stronger association with in-role behaviors.

The results of the current investigation have implications for theory and practice. It has been well accepted that organizational participants typically engage in multiple exchange relationships and derive different benefits from each exchange (Gergen, Greenberg, \& Willis, 1980 ). Our results extend social exchange theory by suggesting that each exchange relationship may differentially affect behaviors and attitudes. Combining past research on social exchange with the current results suggests that multiple exchange relationships are needed both by employees and by organizations. Employees secure different forms of resources and support from each exchange relationship, and organizations benefit from different desired employee attitudes and behaviors that are associated with each exchange relationship. Thus, our findings are also important to practice for suggesting that each exchange relationship may be associated with different employee behaviors. This implies that the process of changing employee attitudes and behaviors may be even more complex than originally thought ( cf. Krackhardt \& Hanson, 1993).

There are a number of limitations with the current investigation. First, the study was nonexperimental. Statements of causality based on the results of even the most sophisticated statistical techniques for making causal inferences, including structural equation modeling, must be treated with caution when using nonexperimental designs. Although the results are consistent with our proposed causal model, it must be noted that causal inferences are unwarranted.

Second, although all but two supervisors who were asked to participate declined, slightly over one half of the prospective nonmanagerial participants did not return their questionnaires. It is possible that responses of those not choosing to participate may have differed from those who did. Also, because the nonmanagerial sample was primarily composed of White women, generalizability to men and members of other races is not guaranteed. Strengths of the study include the collection of endogenous variables from a different source than the exogenous variables (with the exception of organizational commitment), acting to reduce the possibility of common method variance response bias.

A problem afflicting nearly all leader-member ex- change research that has included leader assessments of subordinate behaviors may have influenced the results of the current study. That is, the same factors influencing the quality of the leader-member exchange relationship may also affect leader evaluations of subordinate behavior. In fact, although correlations between performance ratings and leader-member exchange are typically significant (Liden \& Graen, 1980; Wayne \& Ferris, 1990) objective performance and leader-member exchange tend to be unrelated (Duarte, Goodson, \& Klich, 1994; Vecchio \& Gobdel, 1984) or weakly related (Wayne \& Ferris, 1990). A rare field study including both an objective measure of performance and supervisory ratings showed that for high leader-member exchange relationships, leaders are more likely to rate the subordinate's performance favorably regardless of actual performance (Duarte et al., 1994). It has also been found that leaders are more likely to attribute ineffective performance to internal causes for low leader-member exchange subordinates relative to high leader-member exchange subordinates. Similarly, leaders tend to make internal attributions for effective performance of high, but not low, leader-member exchange subordinates (Heneman, Greenberger, \& Anonyuo, 1989).

The generalizability of the findings of the current study should be treated with caution. It is likely that the means through which individuals choose to discharge their obligations in various exchange relationships is dependent on a number of contextual variables such as the needs or interests of the exchange parties or the frequency or sincerity with which the gestures of goodwill are given. With respect to the proposed relationships in the present study, there may be situations in which individuals may perceive that both commitment and work behavior are necessary for discharging their obligations to the organization, the supervisor, both, or neither. Future research should attempt to identify such conditions.

Additionally, in future research we suggest that other types of exchange relationships, as well as an augmented set of behaviors and attitudes be examined in a variety of organizations. In the current study, the work units were structured quite traditionally, with subordinates under the direct control of a supervisor. In less traditional work settings, such as those in which employees experience decision-making control through participation in task interdependent teams, a relatively large set of exchange relationships may emerge. In addition to leader-member exchanges, employees may develop lucrative exchange relationships with team members, as well as individuals in other parts of the organization or even outside of the organization (Brass, 1984; Ibarra, 1993; Krackhardt \& Brass, 1994). Each of these exchange relationships may influence a range of behaviors and attitudes in addition to performance and citizenship, such as work satisfaction, 
coworker satisfaction, turnover, and absenteeism. One type of social exchange that has been shown to be of particular importance is the mentoring relationship (Whitely, Dougherty, \& Dreher, 1991). It may be useful in future investigations to integrate mentorship within the larger set of exchange relationships in which organizational members participate. As organizations become less hierarchically structured, the study of multiple social exchange relationships may be critical in the study of organizational behavior.

\section{References}

Anderson, J. C., \& Gerbing, D. W. (1988). Structural equation modeling in practice: A review and recommended two-step approach. Psychological Bulletin, 103, 411-423.

Becker, T. E. (1992). Foci and bases of commitment: A re they distinctions worth making? Academy of Management Journal, 35, 232-244.

Bentler, P. M. (1985). Theory and implementation of EQS: $A$ structural equations program. Los Angeles: BMDP Statistical Software.

Bentler, P. M., \& Bonett, D. G. (1980). Significance tests and goodness of fit in the analysis of covariance structures. Psychological Bulletin, 88, 588-606.

Bentler, P. M., \& Chou, C. P. (1987). Practical issues in structural modeling. Sociological Methods \& Research, 16, 78117.

Blau, P. (1964). Exchange and power in social life. New York: Wiley.

Brass, D. J. ( 1984). Being in the right place: A structural analysis of individual influence in an organization. Administrative Science Quarterly, 29, 518-539.

Carsten, J. M., \& Spector, P. E. (1987). Unemployment, job satisfaction, and employee turnover: A meta-analytic test of the Muchinsky model. Journal of Applied Psychology, 72, 374-381.

Dansereau, F., Graen, G., \& Haga, W. J. (1975). A vertical dyad linkage approach to leadership within formal organizations: A longitudinal investigation of the role making process. Organizational Behavior and Human Performance, 13, 4678.

Duarte, N. T., Goodson, J. R., \& Klich, N. R. ( 1994). Effects of dyadic quality and duration on performance appraisal. Academy of Management Journal, 37, 499-521.

Eisenberger, R., Fasolo, P., \& Davis-LaMastro, V. (1990). Perceived organizational support and employee diligence, commitment, and innovation. Journal of Applied Psychology, 75, 51-59.

Eisenberger, R., Huntington, R., Hutchison, S., \& Sowa, D. (1986). Perceived organizational support. Journal of Applied Psychology, 71, 500-507.

Etzioni, A. (1961). A comparative analysis of complex organizations. New York: Free Press.

Farkas, A. J., \& Tetrick, L. E. (1989). A three-wave longitudinal analysis of the causal ordering of satisfaction and commitment on turnover decisions. Journal of Applied Psychology, $74,855-868$.
Foa, U. G., \& Foa, E. B. ( 1980). Resource theory: Interpersonal behavior as exchange. In K. S. Gergen, M. S. Greenberg, \& R. H. Willis (Eds.), Social exchange: Advances in theory and research (pp. 77-94). New York: Plenum Press.

Gergen, K. S., Greenberg, M. S., \& Willis, R. H. (1980). Social exchange: Advances in theory and research. New York: Plenum Press.

Gouldner, A. W. (1960). The norm of reciprocity. American Sociological Review, 25, 165-167.

Graen, G., Novak, M. A., \& Sommerkamp, P. (1982). The effects of leader-member exchange and job design on productivity and satisfaction: Testing a dual attachment model. Organizational Behavior and Human Performance, 30, 109131.

Graen, G. B., \& Scandura, T. A. (1987). Toward a psychology of dyadic organizing. Research in Organizational Behavior, 9, 175-208.

Greenberg, M. S. (1980). A theory of indebtedness. In K. S. Gergen, M. S. Greenberg, \& R. H. Willis (Eds.), Social exchange: Advances in theory and research (pp. 3-26). New York: Plenum Press.

Greenberg, M. S., \& Westcott, D. R. ( 1983). Indebtedness as a mediator of reactions to aid. In J. D. Fisher, A. Nadler, \& B. M. DePaulo (Eds.), New directions in helping (Vol. 1, pp. 85-112). New York: Academic Press.

Hayduk, L. A. (1987). Structural equation modeling with LISREL: Essentials and advances. Baltimore: Johns Hopkins Press.

Heneman, R. L., Greenberger, D. B., \& Anonyuo, C. (1989). Attributions and exchanges: The effects of interpersonal factors on the diagnosis of employee performance. Academy of Management Journal, 32, 466-476.

Ibarra, H. (1993). Network centrality, power and innovation involvement: Determinants of technical and administrative roles. Academy of Management Journal, 36, 471-501.

James, L. R., Mulaik, S. A., \& Brett, J. M. ( 1982). Causal analysis: Assumptions, models, and data. Beverly Hills, CA: Sage.

Katz, D., \& Kahn, R. L. ( 1966). The social psychology of organizations. New York: Wiley.

Kenny, D. A. (1979). Correlation and causality. New York: Wiley.

Konovsky, M. A., \& Pugh, S. D. (1994). Citizenship behavior and social exchange. Academy of Management Journal, 37 , 656-669.

Krackhardt, D., \& Brass, D. J. (1994). Intraorganizational networks: The micro side. In S. Wasserman \& J. Galaskiewicz (Eds.), Advances in network analysis (pp. 207-229). Thousand Oaks, CA: Sage.

Krackhardt, D., \& Hanson, J. R. (1993). Informal networks: The company behind the chart. Harvard Business Review, 4 , 104-111.

Levinson, H. (1965). Reciprocation: The relationship between man and organization. Administrative Science Quarterly, 9 , 370-390.

Liden, R. C., \& Graen, G. (1980). Generalizability of the vertical dyad linkage model of leadership. Academy of Management Journal, 23, 451-465.

Liden, R. C., \& Maslyn, J. M. (1993, August). Scale development for a multidimensional measure of leader-member ex- 
change. Paper presented at the Annual Meeting of the Academy of Management, Atlanta, GA.

Manogran, P., \& Conlon, E. J. (1993, August). A leader-member exchange approach in explaining organizational citizenship behavior. Paper presented at the meeting of the Academy of Management, Atlanta, GA.

March, J. G., \& Simon, H. A. (1958). Organizations. New York: Wiley.

Mathieu, J. E., \& Zajac, D. M. (1990). A review and metaanalysis of the antecedents, correlates, and consequences of organizational commitment. Psychological Bulletin, 108, 171-194.

McNeely, B. L., \& Meglino, B. M. (1994). The role of dispositional and situational antecedents in prosocial organizational behavior: An examination of the intended beneficiaries of prosocial behavior. Journal of Applied Psychology, 79, 836844.

Michaels, C. E., \& Spector, D. E. (1982). Causes of employee turnover: A test of the Mobley, Griffeth, Hand, and Meglino model. Journal of Applied Psychology, 67, 53-59.

Moorman, R. H. (1991). Relationship between organizational justice and organizational citizenship behaviors: Do fairness perceptions influence employee citizenship? Journal of Applied Psychology, 76, 845-855.

Mowday, R. T., Steers, R. M., \& Porter, L. W. (1979). The measurement of organizational commitment. Journal of Vocational Behavior, 14, 224-247.

Organ, D. W. ( 1988). Organizational citizenship behavior: The good soldier syndrome. Lexington, MA: Lexington Books.

Organ, D. W., \& Konovsky, M. (1989). Cognitive versus affective determinants of organizational citizenship. Journal of Applied Psychology, 74, 157-164.

Platt, J. R. (1964). Strong inference. Science, 146, 347-353.

Reichers, A. E. (1985). A review and reconceptualization of organizational commitment. Academy of Management Review, 12, 460-471.

Reichers, A. E. (1986). Conflict and organizational commitments. Journal of Applied Psychology, 71, 508-514.

Robinson, S. L., Kraatz, M. S., \& Rousseau, D. M. (1994). Changing obligations and the psychological contract: A lon- gitudinal study. Academy of Management Journal, 37, 137152.

Rousseau, D. M. (1989). Psychological and implied contracts in organizations. Employee Responsibilities and Rights Journal, 2, 121-139.

Scholl, R. W. (1981). Differentiating organizational commitment from expectancy as a motivating force. Academy of Management Review, 6, 589-599.

Shore, L. M., \& Wayne, S. J. (1993). Commitment and employee behavior: Comparison of affective commitment and continuance commitment with perceived organizational support. Journal of Applied Psychology, 78, 774-780.

Van Dyne, L., Graham, J. W., \& Dienesch, R. M. (1994). Organizational citizenship behavior: Construct redefinition, measurement, and validation. Academy of Management Journal, 37, 765-802.

Vecchio, R. P., \& Gobdel, B. C. (1984). The vertical dyad linkage model of leadership: Problems and prospects. Organizational Behavior and Human Performance, 34, 5-20.

Wayne, S. J., \& Ferris, G. R. (1990). Influence tactics, affect, and exchange quality in supervisor-subordinate interactions: A laboratory experiment and field study. Journal of Applied Psychology, 75, 487-499.

Wayne, S. J., \& Green, S. A. ( 1993). The effects of leader-member exchange on employee citizenship and impression management behavior. Human Relations, 46, 1431-1440.

Whitely, W., Dougherty, T. W., \& Dreher, G. R. (1991). Relationship of career mentoring and socioeconomic origin to managers and professionals' early career progress. Academy of Management Journal, 34, 331-351.

Williams, L. J., \& Anderson, S. E. (1991). Job satisfaction and organizational commitment as predictors of organizational citizenship and in-role behaviors. Journal of Management, $17,601-617$.

Williams, L. J., \& Hazer, J. T. ( 1986). Antecedents and consequences of satisfaction and commitment in turnover models: A reanalysis using latent variable structural equation methods. Journal of Applied Psychology, 71, 219-231.

Received May 1, 1995

Revision received October 19, 1995 Accepted December 5, 1995 